\title{
EARLY TRACKING THROUGH MAMMOGRAPHY IN BREAST CANCER DETECTION IN WOMEN IN BRAZIL FROM 2015 TO 2019: EPIDEMIOLOGICAL STUDY
}

Antonio Márcio Teodoro Cordeiro Silva, Liliane Emilly dos Santos Sousa², Camila de Assunção Martins, Bárbara de Magalhães Souza Gomes¹, Jacqueline Andréia Bernardes Leão-Cordeiro³, Fábio Silvestre Ataides', Cesar Augusto Sam Tiago Vilanova-Costa ${ }^{4}$

1Pontifícia Universidade Católica de Goiás - Goiânia, (GO), Brazil.

2Universidade Paulista - Goiânia, (GO), Brazil.

3Universidade Federal de Goiás - Goiânia, (GO), Brazil.

${ }^{4}$ Associação de Combate ao Câncer em Goiás - Goiânia, (GO),Brazil.

Objectives: To analyze the aspects of mammography in the early screening of breast cancer, in Brazil, from 2015 to 2019. Methodology: Descriptive epidemiological study, with secondary data extracted from the Department of Informatics of the Brazilian Unified Health System (DATASUS), through the Cancer Information System (SISCAN). Information related to mammography examinations was classified by place of care according to the clinical indication (screening or diagnosis), age group ( $<40->70$ years), previous mammography, high risk of breast cancer (BC), examination completion time, and the Breast Imaging Reporting and Data System (BI-RADS ${ }^{\circledR}$ ), which classifies radiological findings as 0 (undefined), 1 (negative), 2 (benign), 3 (probably benign), 4 (suspect), 5 (highly suspicious), and 6 (diagnosed with cancer). Results: Between 2015 and 2019, 3,031,607 mammograms were performed in Brazil, of which 2,955,262 occurred by screening and 76,345 by clinical diagnostic indication. Among the screening mammograms, $63.2 \%$ were performed on women in the age group recommended by the Brazilian Ministry of Health (MS), from 50 to 69 years old. The previous history of this examination was confirmed by $2,300,995$ women, where $17.5 \%$ were at high risk for BC. For the examination time, 1,396,105 mammograms took place within 30 days, and 775,971 and 859,531 over 60 days. BI-RADS was higher in category 2 (1,520,469 mammograms), followed by category 1 with 1,071,514 of mammograms, and in the target population recommended by the Brazilian Ministry of Health, the largest number of tests was concentrated in BI-RADS category 2 with $34.2 \%$. Conclusion: Characterization of the main aspects involved in mammography, such as age, high risk, and among others, allows to infer that the early screening of $\mathrm{BC}$ when prioritized by public health policies, aiming at the promotion of women's health, impacts on the early detection and the reduction of the incidence and mortality by $\mathrm{BC}$ in women in Brazil.

Key words: Breast Cancer; Early Detection; Mammography; Screening. 